\title{
The Impact of Chronic Periodontitis on Mother-Infant Bonding Status in Relation to Salivary Tumor Necrosis Factor Alpha and Interleukin-6
}

Liqa Sabah Hassan, B.D.S, M.Sc. (1)

Ban Sahib Diab B.D.S, M.Sc., Ph.D. (2)

\begin{abstract}
Background: Chronic periodontitis is a bacterial infection that result in bone destruction associated with the increasing level of salivary tumor necrosis alpha and interleukin6 that affect Mother-infant bonding status. The aim of the present study was to assess the relationship between the Mother-infant bonding status in mothers with chronic periodontitis in relation to Salivary Tumor necrosis factor alpha and Salivary Interleukin6.

Materials and Methods: The selected sample consisted of mothers with chronic periodontitis compared with mothers with healthy periodontium in postpartum period, their age ranged between 30-40 years. Both groups were subjected to postpartum Bonding Questionnaire (PBQ). Periodontal health status was assessed for control group like plaque index and gingival index in order to obtain control group with healthy periodontium, while measuring probing pocket depth and clinical attachment level in addition to plaque and gingival index for study group. Salivary Tumor necrosis factor alpha and Interleukin6 measure in saliva by enzyme-linked immune sorbent assay (ELISA).

Results: The mean values of Salivary Tumor necrosis factor alpha and Interleukin 6 were found to be higher among mothers with chronic periodontitis than mothers with normal bonding relationship, and the percentage of disorder mother-infant bonding relation was higher in study group than in control group.

Conclusion: Mother-infant bondings affected by chronic periodontitis as the patient have higher Salivary Tumor necrosis factor alpha and Salivary Interleukin6 than mothers with healthy periodontal condition.
\end{abstract}

Key words: Chronic periodontitis, Mother-infant bonding, salivary tumor necrosis factor alpha, salivary interleukinb. (Received 1/4/2019; Accepted 5/5/2019)

\section{INTRODUCTION}

Periodontitis is a bacterial infection produced by various oral microorganisms ${ }^{(1)}$. Which results in the formation of soft tissue pockets and its severe forms can lead to bone loss or tooth mobility. Although bacteria are essential for periodontal disease to take place, susceptible host is also just as important. Host inflammatory response is a defensive reaction but both hypo-responsiveness and hyper-responsiveness can result in advanced tissue destruction ${ }^{(2)}$.

Periodontitis was resulted mainly to untreated gingivitis, Chronic periodontitis may occur as a localized disease in which less than $30 \%$ of examined periodontal sites demonstrate clinical attachment and bone loss. Moreover, it may occur as a more generalized disease with more than $30 \%$ of sites was affected ${ }^{(3)}$.

Maternal-newborn bonding is a concept used throughout the obstetrical and pediatric fields, but not widely known amongst all clinicians. The connection made after birth directly affects both the mother and newborn physiologically, psychologically and emotionally. A strong bond formed between a mother and infant leads to positive outcomes and impacts the maternal child relationship through the lifespan. "The parentinfant bond provides a foundation for future adaptation, relationships, and mental health for children and adults" (4).

(1) Ph.D. Student, Department of Periodontology, College of Dentistry, University of Baghdad.
(2) Professor, Department of Pedodontic and Preventive Dentistry, College of Dentistry, University of Baghdad.

In the postpartum period, the initiation and progression of the connection between the mother and her infant is an important psychological step that presented as a challenge to the mother. Bonding is the term usually used to describe this relationship ${ }^{(5)}$.

The negative response of the mother toward the infant's stimuli is called 'Maternal bonding disorder' (6). There are many manifestations of bonding disorder: delay, ambivalence or loss in maternal response, threatened or established rejection, pathological anger, and infant abuse ${ }^{(7)}$.

The attachment theory that was constructed by Bowlby, $2008{ }^{(8)}$. Proposed that the person requires or needs to form an affectionate connection with a caregiver (mainly the mother) from the unborn phase and as getting older this emotional requisite is beyond the feeding needs. As a child, these psychological actions are wanted to create comforting, protecting, warm, and loving feelings. Some factors have the potential to create barrier that affect the bonding process which include a lack of support, the riskiness of the pregnancy, maternal fatigue, and lack of confidence in parenting abilities, other factors that influence negatively or positively the bonding relationship include: pattern of infant feeding 9 , 10), depression (11), separation of the premature infant from the mother after birth ${ }^{(12,13)}$, and others. The quality of the maternal-newborn relationship can have a significant impact on the 
mother's mental health and newborn's wellbeing, development, and adaptation throughout life ${ }^{(14)}$.

Several questionnaires have been produced to evaluate the bonding status, even though the postpartum bonding questionnaire (PBQ) which was introduced by Brockington et al., 2006 had been largely studied regarding the validity and reliability which was easy to be applied ${ }^{(15,16)}$.

Tumor Necrosis Factor Alpha (TNF- $\alpha$ ) is one of the important periodontal pathogens-induced by early inflammatory cytokines in the destructive periodontal disease ${ }^{(17)}$. Elevated levels of TNF- $\alpha$ are well-known risk factor for the destructive periodontal disease ${ }^{(18)}$. It is contributing to the beginning of the destructive periodontal disease via several mechanisms. Examples of these mechanisms are: (i) TNF- $\alpha$ prompts the destruction of the alveolar bone by stimulating the formation of bone-resorbing cells (osteoclasts) (19); (ii) TNF- $\alpha$, is considered as a one of the early promoters of the host response to the periodontal bacterial pathogens, regulates the matrix metalloproteinase (MMPs), which are capable of degrading the connective tissues. Interestingly, studies on the immune response to periodontal pathogens exhibited that TNF- $\alpha$ enhanced the immune response to these pathogens (20). Interleukin-6 (IL-6) is a cytokine with an extensive range of biological activities. It is a mediator for the immunoglobulin substituting and it has a role in controlling the acute phase response. It is also an inflammatory indicator within body ${ }^{(21)}$. For the occurrence of bacteremia, IL-6 can also use as an investigative marker. Interleukin-6 is produced by innate immune cells such as macrophages and dendritic cells but also by some $\mathrm{CD} 4+$, T-cells in addition to nonimmune cells such as fibroblasts and endothelial cells ${ }^{(22)}$. Interleukin-6 is elevated in many inflammatory diseases and mainly functions to activate B-lymphocytes furthermore it has a role in influencing the balance of CD4+ effector on Tcell populations and potentially influencing myeloid cell differentiation ${ }^{(23)}$. As far there is no previous Iraqi study concerning the effect of chronic periodontitis through the inflammatory mediators on the bonding between lactating mothers and their infants, this study was conducting in order to find the relation between salivary TNF- $\alpha$ and IL- 6 on the bonding status.

\section{MATERIALS AND METHODS}

The selected sample composed of 90 lactating mothers aged 30-40 years where 45 lactating mothers were with chronic periodontitis and they represent the study group. They were selected according to the criteria of chronic periodontitis which involved gingival recession resulting from loss of attachment and alveolar bone loss, pocket formation, loss of periodontal attachment, loss of alveolar bone, root furcation exposure and tooth mobility in advanced cases of bone destruction) (24). Forty-five lactating mothers with healthy periodontium were selected to represent the control group. The participants were informed about the aim of the study and they were freely allowed to accept the examination. Informed consent and ethical approval had been obtained. The participants were selected and examined in the health centers of Diyala governorate and ruler area during the attendance to the primary health care for the purpose of vaccination. Exclusion criteria involved mothers who were unwilling to participate in the study, those who were on contraceptive pills or other medications, pregnancy, smoking, and systemic diseases. Unstimulated salivary samples were collected from the mothers. The mothers were advised refrain from intake of any food or beverage (water exempted) one hour before the test session. The mothers were advised to rinse their mouth several times with distilled water and then to relax for five minutes. The mothers should minimize movements, particularly mouth movements during collection and lean the head forward keeping the mouth slightly opened to allow saliva to drain into the tube. For the salivary pro-inflammatory cytokines, TNF alpha and IL6were measured in both groups of the lactating mothers using ELISA Kit and the enzyme-linked immune sorbent assay (ELISA).The Postpartum Bonding Questionnaire (PBQ) was used to estimate the mother-infant bonding relationship status (25). The PBQ has twenty-five statements, each followed by 6 alternative replies. A high score signals pathological condition. The questionnaire has four factors: general factor, rejection and pathological anger, anxiety about the infant and incipient abuse. In this study, a total score of 19 attained the maximum split between mothers with normal mother-infant relationship and those with some type of disorder, the total scores of all items of the questionnaire has a maximum of 125 . The mothers who attended the health centers were asked to complete all the components of the Postpartum Bonding Questionnaire by themselves without assistance or discussing the answers with others. Oral examinations were done under standardized conditions according to the basic methods of oral health surveys of World Health Organization ${ }^{(26)}$. The pocket depth was measured using calibrated periodontal probes (William's 
probes) at four surfaces of all the examined teeth except the third molars. The sites for the measurements were mid-buccal, mid-palatal, mesiobuccal and distobuccal lines A scale was used for the ease of estimation ${ }^{(27)}$ :

Score 0: 1-3mm

Score 1: > 3-5mm

Score 2: $>5-7 \mathrm{~mm}$

Score 3: $>7 \mathrm{~mm}$

The attachment loss was measured by using the periodontal probe at four sites for all examined teeth except third molar by:

1. Measuring the distance from the free gingival margin to the cemento-enamel junction.

2. Measuring the distance from free gingival margin to the bottom of the sulcus or pocket at each site. The interproximal recording should be secured at the buccal aspect of the interproximal contact.

3. The attachment loss was obtained from subtracting the first measurement from the second one.

4. Recession was recorded as a negative value that means the attachment loss was obtained from adding the first measurement to the second one. Clinical attachment loss readings were divided into 4 scores ${ }^{(28)}$ :

Score 1: 1-3 mm

Score 2: > 3-5mm

Score 3: $>5-7 \mathrm{~mm}$

Score 4: $>7 \mathrm{~mm}$

\section{RESULTS}

Distribution of the mothers according to infant bonding status is illustrated in Table 1 that shows the percentage of the disordered mother which was $95.56 \%$ for the study group while for the control group the opposite figure was found as the percentage of the disordered mothers was only $4.44 \%$.

Table 1: Mother-infant bonding status distribution

\begin{tabular}{|c|c|c|c|c|}
\hline \multirow{2}{*}{\multicolumn{3}{|c|}{$\begin{array}{c}\text { Mother-infant bonding } \\
\text { status }\end{array}$}} & \multicolumn{2}{|c|}{$\begin{array}{l}\text { Mother-infant } \\
\text { bonding status }\end{array}$} \\
\hline & & & normal & disorder \\
\hline \multirow{6}{*}{ Groups } & \multirow{3}{*}{ Study } & Number & 2 & 43 \\
\hline & & $\begin{array}{c}\% \text { within } \\
\text { groups }\end{array}$ & 4.44 & 95.56 \\
\hline & & $\begin{array}{l}\% \text { of } \\
\text { Total }\end{array}$ & 2.22 & 47.78 \\
\hline & \multirow{3}{*}{ Control } & Number & 43 & 2 \\
\hline & & $\begin{array}{l}\% \text { within } \\
\text { groups }\end{array}$ & 95.56 & 4.44 \\
\hline & & $\begin{array}{l}\% \text { of } \\
\text { Total }\end{array}$ & 47.78 & 2.22 \\
\hline
\end{tabular}

The results revealed a positive correlation between mother-infant bonding status and the mean of the probing pocket depth and the mean of the clinical attachment level, although the results were not significant statistically as shown in Table 2.

Table 2: Correlation Coefficient between Mother-infant bonding status and periodontal parameters (Probing pocket depth and Clinical attachment level).

\begin{tabular}{|c|c|c|}
\hline $\begin{array}{c}\text { Periodontal } \\
\text { parameters }\end{array}$ & r & p value \\
\hline $\begin{array}{c}\text { Probing pocket depth } \\
\text { score 1 }\end{array}$ & 0.007 & 0.962 \\
\hline $\begin{array}{c}\text { Probing pocket depth } \\
\text { score 2 }\end{array}$ & -0.111 & 0.467 \\
\hline $\begin{array}{c}\text { Probing pocket depth } \\
\text { score 3 }\end{array}$ & 0.181 & 0.235 \\
\hline $\begin{array}{c}\text { Probing pocket depth } \\
\text { mean }\end{array}$ & 0.124 & 0.418 \\
\hline $\begin{array}{c}\text { Clinical attachment } \\
\text { level score 1 }\end{array}$ & -0.146 & 0.339 \\
\hline $\begin{array}{c}\text { Clinical attachment } \\
\text { level score 2 } \\
\text { level score 3 }\end{array}$ & 0.036 & 0.812 \\
\hline $\begin{array}{c}\text { Clinical attachment } \\
\text { level mean }\end{array}$ & 0.250 & 0.097 \\
\hline $\begin{array}{c}\text { Clinical attachment } \\
\text { evel }\end{array}$ & 0.215 & 0.156 \\
\hline
\end{tabular}

The results report that mother-infant bonding relation among the study and the control group had positive correlations with salivary TNF alpha and salivary IL6. However, the results were not statistically significant among the study group in relation to IL6 and in relation to TNF alpha, while it was significant among the control group in relation to IL6 and in relation to TNF alpha as illustrated in Table 3.

Table 3: Relation between Mother-infant bonding status and Salivary IL6, Salivary

\begin{tabular}{|c|c|c|c|c|}
\multicolumn{4}{c}{ TNF } \\
\hline \multirow{2}{*}{ Group } & \multicolumn{2}{|c|}{ IL6 } & \multicolumn{2}{c|}{ TNF - $\boldsymbol{\alpha}$} \\
\cline { 2 - 5 } & $\mathbf{r}$ & $\mathbf{p}$ & $\mathbf{r}$ & $\mathbf{p}$ \\
\hline Study & 0.257 & 0.088 & 0.050 & 0.746 \\
\hline Control & 0.290 & 0.053 & 0.309 & 0.039 \\
\hline
\end{tabular}

\section{DISCUSSION}

Since there are no available previous Iraqi studies concerning the relationship between motherinfant bonding and periodontal health status, this study was conducted to investigate the impact of the periodontal health on the maternal bonding. The result of the present study showed that the percentage of the disordered mothers was higher among the study group than that found among the control group, this could demonstrate the association between the chronic periodontitis and 
the mother-infant bonding status and can be explained as bidirectional. This finding also confirmed by the results of the present study that demonstrated a positive relation with probing pocket depth score 1 and 3 , and clinical attachment level score 2 and 3. One mechanism that had been proposed for the chronic periodontitis as a hazard factor for other systemic diseases comprises systemic dissemination of oral bacteria and inflammatory mediators ${ }^{(29)}$ and that belong to the proinflammatory common systemic mediators such as TNF- $\alpha$ and IL-6. Remarkably, it had been shown that these cytokines were increased in the gingival crevicular fluid in patients with chronic periodontitis who did not have chronic systemic diseases ${ }^{(30)}$. It had been detected that immunological activation induces stress-like behavioral and neurochemical changes in organs of humans ${ }^{(31)}$.As the current study showed a positive relation between mother-infant bonding status and salivary TNF, IL6 and these proinflammatory cytokines along with other compounds such as corticotropin releasing hormone $(\mathrm{CRH})$ are obviously involved in the pathogenesis of stress ${ }^{(32)}$. Activation of cytokine receptors and changes in cytokine are thought to play important roles in neuronal dysfunction and pathogenesis of stress ${ }^{(33)}$. Trigger factors may induce depressive symptoms. In addition activated protein kinase (AMPK) which is tightly controlled by the cellular AMP/ATP ratio, plays a central role in the regulation of energy; homeostasis and metabolic stress ${ }^{(34)}$. Cytokines are also involved in stress response and participate in neurochemical, behavioral and endocrine changes due to illness, IL6 increases following a neurogenic inflammatory stimulus (35).

In conclusion, the periodontal health status of the mother influences the maternal bonding status, so recognition and identification of the periodontal health status would allow psychological intervention to improve the motherinfant bonding relation. However, further studies are needed to determine the effect of biomarkers in relation to oral health status to investigate the exact impact of chronic periodontitis on the bonding status of the mothers.

\section{REFRENCES}

1. Zhang L, Henson BS, Camargo PM, Wong DT. The clinical value of salivary biomarkers for periodontal disease. Periodontology 2000. 2009;51(1):25-37.

2. Pihlstrom BL, Michalowicz BS, and Johnson NW. Periodontal diseases. Lancet 2005: 366: 1809-1820

3. Petersen, P.E., Bourgeois, D., Ogawa, H., et al. The global burden of oral diseases and risks to oral health.
(2005) Bull World Health Organ 83(9): 661669.Pubmed | Others

4. Spratt EG, Marsh C, Wahlquist AE, Papa CE, Nietert PJ, et al. (2016) Biologic effects of stress and bonding in mother-infant pairs. Int J Psychiatry Med 51: 246257.

5. Brockington I. Postpartum psychiatric disorders. Lancet 2004; 363: 303-10.

6. Kumar RC. Anybody's child: Severe disorders of mother-to-infant bonding. Brit J Psychiat 1997; 171: 175-81.

7. Brockington IF, Oates J, George S, Turner D, Vostanis P, Sullivan M, et al. A screening questionnaire for mother-infant bonding disorders. Arch Women's Ment Health 2001; 3: 133-40.

8. Bowlby J. Attachment. 2nd ed. New York: Basic Books, 2008.

9. Ross E. Maternal-fetal attachment and engagement with antenatal advice. Brit J Midwifery 2012; 20(8): 566-75.

10. Kim P, Feldman R, Mayes LC, Eicher V, Thompson $\mathrm{N}$, Leckman JF, Swain JE. Breastfeeding, brain activation to own infant cry, and maternal sensitivity. J Child Psychol Psychiatry 2011; 52(8): 907-15.

11. O'Higgins M, Roberts IS, Glover V, Taylor A. Mother- child bonding at 1 year; associations with symptoms of postnatal depression and bonding in the first few weeks. Arch Women's Ment Health 2013; 16(5): 381-9.

12. Fegran L, Helseth S, Fagermoen M. A comparison of mothers' and fathers' experiences of the attachment process in a neonatal intensive care unit. J Clin Nursing 2008; 17(6): 810-6.

13. Henry S, Richard-Yris M, Tordjman S, Hausberger M. Neonatal handling affects durably bonding and social development. Plos ONE 2009; 4(4): 1-9.

14. Brockington IF, Fraser C, Wilson D. The Postpartum Bonding Questionnaire: a validation. Arch Women's Ment Health 2006; 9: 233-42.

15. Garcia-Esteve L, Torres A, Lasheras G, PalaciosHernández B, Farré-Sender B, Subirà S, ValdésIan M, Brockington IF. Assessment of psychometric properties of the postpartum bonding questionnaire (PBQ) in spanish mothers. Arch Women's Ment Health 2016; 19(2): 385-94.

16. Ohashi Y, Kitamura T, Sakanashi K, Tanaka T. Postpartum bonding disorder: factor structure, validity, reliability and a model comparison of the postnatal bonding questionnaire in Japanese mothers of infants. Healthcare 2016; 4:50.

17. D. T. Graves and D. Cochran, "The contribution of interleukin-1 and tumor necrosis factor to periodontal tissue destruction," Journal of Periodontology, vol. 74, no. 3, pp. 391-401, 2003. View at Publisher · View at Google Scholar . View at Scopus

18. D. T. Graves and D. Cochran, "The contribution of interleukin-1 and tumor necrosis factor to periodontal tissue destruction," Journal of Periodontology, vol. 74, no. 3, pp. 391-401, 2003. View at Publisher · View at Google Scholar . View at Scopus

19. K. Kobayashi, N. Takahashi, E. Jimi et al., "Tumor necrosis factor $\alpha$ stimulates osteoclast differentiation by a mechanism independent of the ODF/RANKLRANK interaction," Journal of Experimental Medicine, vol. 191, no. 2, pp. 275-285, 2000. View at Publisher - View at Google Scholar · View at Scopus 
20. D. T. Graves, R. Liu, M. Alikhani, H. Al-Mashat, and P. C. Trackman, "Diabetes-enhanced inflammation and apoptosis-impact on periodontal pathology," Journal of Dental Research, vol. 85, no. 1, pp. 15-21, 2006. View at Publisher. View at Google Scholar. View at Scopus

21. Fuster, J.J. and Walsh, K., 2014. The Good, the Bad, and the Ugly of interleukin- 6 signaling. The EMBO journal, p.e201488856.

22. Rincon M. Interleukin-6: from an inflammatory marker to a target for inflammatory diseases. Trends Immunol 2012: 33: 571-577.

23. Anderson P 2008. Post-transcriptional control of cytokine production. Nature Immunol 9: 353-359

24. Kinane DF. Causation and pathogenesis of periodontal disease. Periodontol 2000. 2001;25:8-20.

25. Johnson K. Maternal infant bonding: A review of literature. Int J Childbirth Educ 2013; 28(3): 17-22

26. World Health Organization. Oral health surveys basic methods. 4th ed. Geneva, Switzerland, 1997.

27. Salvi GE, Lindhe J \& Lang NP. Examination of Patients with periodontal diseases. Clinical periodontology \& implant dentistry. 5th ed. Munksgaard, Copenhagen 2008.

28. American Academy of Periodontology. Parameter on comprehensive periodontal examination. J Periodontol 2000; 71(5): 847-8.

29. Hajishengallis G. Periodontitis: from microbial immune subversion to systemic inflammation. Nat Rev Immunol. 2015; 15:30-44.
30. Reis C, Da Costa AV, Guimarães JT, et al. Clinical improvement following therapy for periodontitis: association with a decrease in IL-1 and IL-6. Exp Ther Med. 2014;8(1):323-327.

31. Maes M., G. Kenis and M. Kubera. 2003. In humans, corticotropin releasing hormone antagonizes some of the negative immunoregulatory effects of serotonin. Neuroendocrinol. Lett. 24:420.

32. Jin Q., B.S. Jhun, S.H. Lee, J. Lee, Y. Pi, Y.H. Cho, H.H. Baik and I. Kang. 2004. Differential regulation of phosphatidylinositol 3-kinase/Akt, mitogenactivated protein kinase, and AMP-activated protein kinase pathways duringmenadione-induced oxidative stress in the kidney of young and old rats.Biochem. Biophys. Res. Commun.3/5:555

33.Nagata D., M. Mogi and K. Walsh. 2003. AMPactivated protein kinase (AMPK) signaling in endothelial cells is essential for angiogenesis in response (0 hypoxic stress. J. Bioi. Chem. 278:3/000.

34. O'Connor K.A., J.D. Johnson, M.K. Hansen, F.J.L. Wieseler, E. Maksimova, L.R. Watkins and S.F. Maier. 2003. Peripheral and central proinflammatory cytokine response to a severe acute stressor. Brain Res. 99/: /23.

35. Kumar H, Kawai T, Akira S 2011. Pathogen recognition by the innate immune system. Int Rev Immunol 30: 16-34

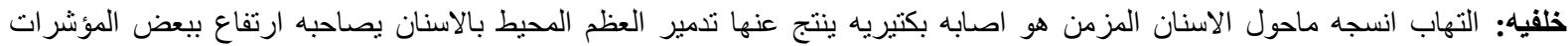

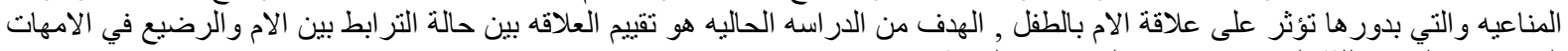

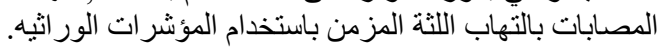

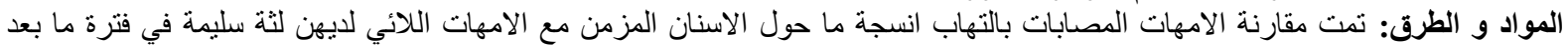

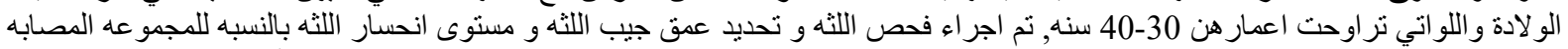

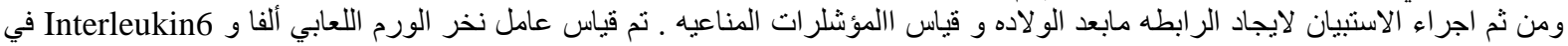

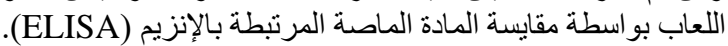

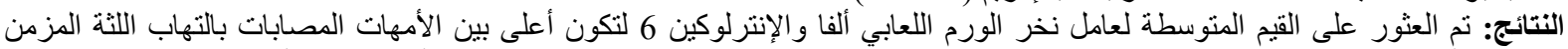

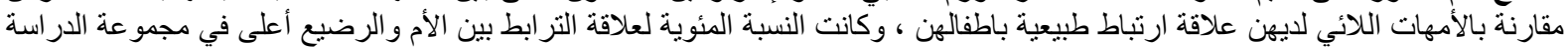

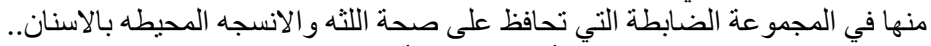

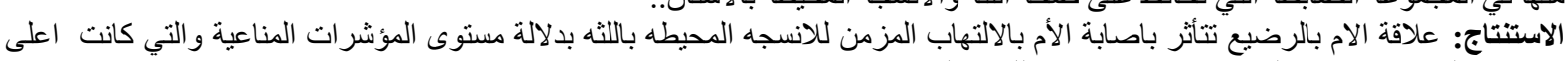

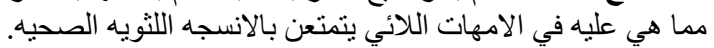

